\title{
Quantification of Milling Rate and Reduction in Amorphous Damage using Low Energy, Small Spot, Argon Ion Milling for TEM Specimens prepared by FIB.
}

\author{
Mina Abadier ${ }^{1}$, Michael Boccabella ${ }^{1}$, Junhai Liu ${ }^{1}$ and Paul Fischione ${ }^{1}$ \\ 1. E. A. Fischione Instruments, Export, PA, USA 15632
}

Focused ion beam (FIB) is an indispensable tool for preparing site-specific transmission electron microscopy (TEM) specimens [1]. However, specimens prepared by FIB typically suffer from amorphous damage, $\mathrm{Ga}^{+}$ion implantation and other artifacts [1, 2]. Low-energy $(<1 \mathrm{kV})$ small-spot $\mathrm{Ar}^{+}$ ion milling has been shown to be an effective tool for post-FIB specimen processing to improve specimen quality $[3,4]$. However, there is not enough information concerning the ion milling rate and quantification of the reduction in amorphous damage. In this work, direct measurement and quantification of the milling rate and amorphous layer thickness were performed for Si TEM specimens prepared using FIB.

Six Si TEM specimens were prepared using a FEI Scios Dualbeam FIB. Specimens (A - C) were dedicated to quantifying the $\mathrm{Ar}^{+}$ion milling rate. These three specimens were thinned to a thickness greater than $400 \mathrm{~nm}$, which allowed for the accurate measurement of specimen thicknesses in a scanning electron microscope (SEM), and for longer ion milling durations, and, consequently, for a higher degree of accuracy in estimating the milling rate. Table 1 summarizes the results of the milling rate study. Fig. 1(a) shows an SEM image of specimen A. The specimen thickness was measured before ion milling by observing the edge of the sample at a high tilt angle $\left(40^{\circ}\right)$ in the SEM, as shown in Fig. 1(b).

$\mathrm{Ar}^{+}$ion milling was performed using Fischione Instruments' Model 1080 PicoMill@- TEM specimen preparation system. Specimen A was a control sample that was not milled in the PicoMill. The purpose of specimen A was to verify the accuracy of the edge-on thickness measurement performed for specimens B and C in the SEM prior to ion milling. Specimen A thickness was verified by preparing a cross-sectional TEM sample from it using the FIB, as shown in Fig. 1(c). The true specimen thickness was accurately measured using a FEI Tecnai TF30 TEM at the [111] zone-axis orientation, as shown in Fig. 1 (d). The error in the SEM thickness measurements was calculated to be less than 5\%.

Table 1 lists the ion milling conditions for specimens B and C. In the PicoMill system, both specimens were milled at an angle of $\pm 10^{\circ}$ for an equal amount of time on both sides of the specimen. The milling area was $15 \times 15 \mu \mathrm{m}$. The ion milling process was continuously monitored in the PicoMill system. Fig. 2 (a) and (b) show SEM images acquired using the PicoMill system before and after ion milling of specimen B, respectively. After milling, cross-sectional TEM specimens were prepared from specimens $\mathrm{B}$ and $\mathrm{C}$; and their thicknesses were accurately measured using the TEM.

Specimens D - F were used to quantify the reduction of the amorphous damage layer. The same approach of using the FIB to prepare a cross-section from a TEM specimen was also employed for this study. This allowed for a direct measurement of the amorphous layer thickness. Final thinning of sample $\mathrm{D}$ was done by $30 \mathrm{kV}(0.1 \mathrm{nA}) \mathrm{Ga}^{+}$FIB. Specimen E was further cleaned in the FIB using a $5 \mathrm{kV}$ (77 pA) beam for 3 minutes on each side of the specimen. Specimen F was further milled using the PicoMill for 4 minutes on each side at $900 \mathrm{eV}$ followed by 4 minutes at $500 \mathrm{eV}$. Cross-sections of all three specimens were then prepared using FIB. Fig. 2(c) shows a high-resolution micrograph of the cross- 
section of specimen D that was prepared at $30 \mathrm{kV}$. The thickness of amorphous damage layer for specimen D was $16 \mathrm{~nm}$. Measurement of amorphous layer thickness for specimens E (5 kV cleaned) and $\mathrm{F}\left(\mathrm{Ar}^{+}\right.$ion milled $)$is currently in progress.

In conclusion, the ion milling rate of $\mathrm{Si}$ was calculated at $900 \mathrm{eV}$ and $500 \mathrm{eV}$. Quantification of the reduction of the amorphous layer thickness and its impact on HRTEM image quality and resolution is currently underway. In the future, this study will be extended to include other materials of interest.

\section{References:}

[1] J Mayer et al, MRS Bulletin 32 (2007), p. 400

[2] KA Unocic et al, Journal of Microscopy 240 (2010), p. 227.

[3] RR Cerchiara et al, Microscopy Today 19 (2011), p. 16

[4] A Lotnyk et al, Microelectronics Reliability 55 (2015), p. 2119

\begin{tabular}{|l|l|l|l|l|l|}
\hline & $\begin{array}{l}\text { Thickness } \\
\text { (before milling) }\end{array}$ & $\begin{array}{l}\text { PicoMill Milling } \\
\text { conditions }\end{array}$ & $\begin{array}{l}\text { Duration } \\
(\text { minutes })\end{array}$ & $\begin{array}{l}\text { Thickness (after } \\
\text { milling) in TEM }\end{array}$ & Milling rate \\
\hline Sample A & $459 \mathrm{~nm}$ & N/A & N/A & $437 \mathrm{~nm}$ & N/A \\
\hline Sample B & $427 \mathrm{~nm}$ & $900 \mathrm{eV} / 140 \mathrm{pA}$ & 80 & $105 \mathrm{~nm}$ & $4.0 \mathrm{~nm} / \mathrm{min}$ \\
\hline Sample C & $438 \mathrm{~nm}$ & $500 \mathrm{eV} / 100 \mathrm{pA}$ & 160 & $340 \mathrm{~nm}$ & $0.6 \mathrm{~nm} / \mathrm{min}$ \\
\hline
\end{tabular}

Table 1. Summary of milling conditions, thickness measurements and milling rates for samples A $-\mathrm{C}$.
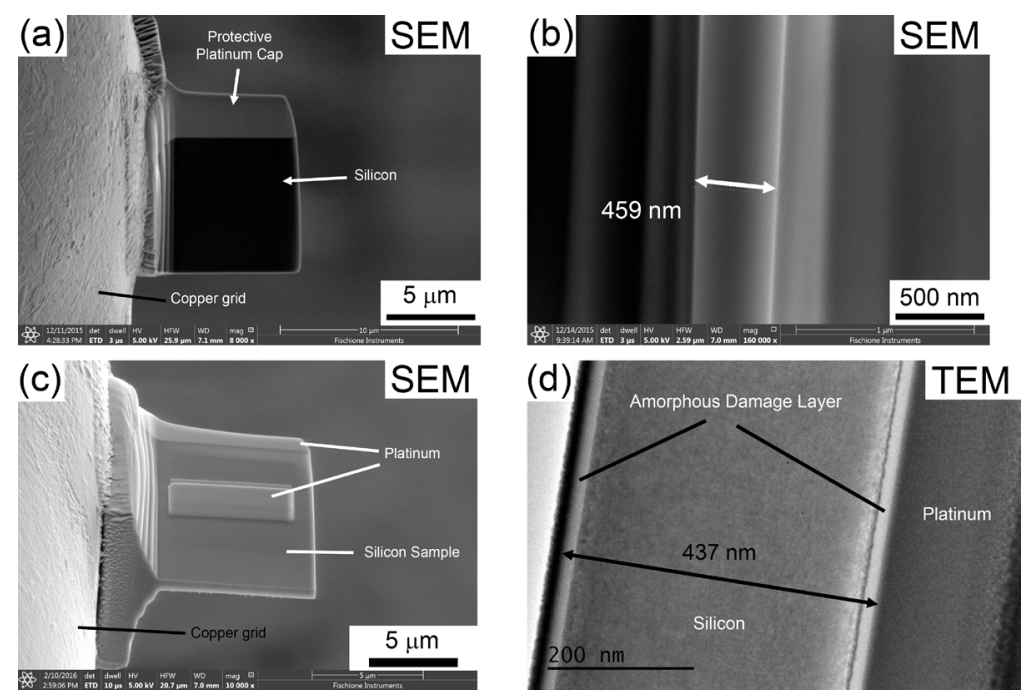

Figure 1. SEM images of sample A (a) after FIB preparation, (b) Edge thickness measurement and (c) Cross-sectional FIB processing. (d) TEM image of sample A cross-section at [111] zone-axis orientation
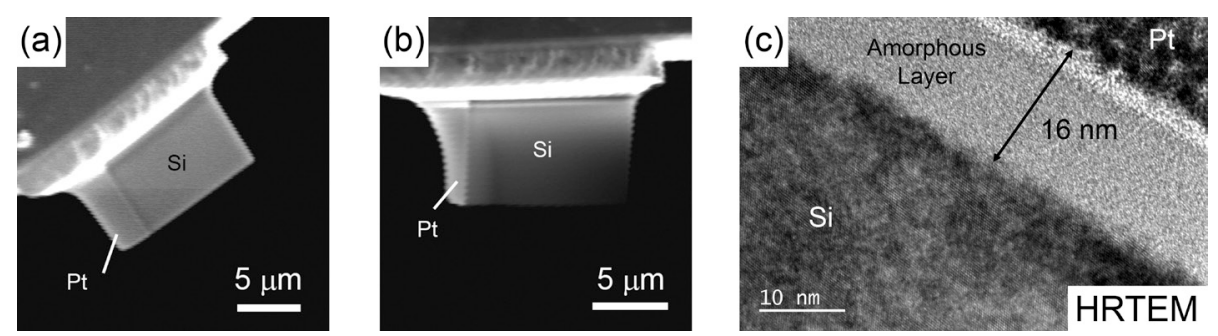

Figure 2. SEM images of sample B (a) before and (b) after ion milling. (c) High-resolution (HRTEM) image of the cross section of sample $\mathrm{D}$ at [111] zone-axis orientation showing amorphous damage layer 